\title{
Reducing Capital Cost and Providing Electricity to Grid by Power Generation from Poultry Farms
}

\author{
Muhammad Bashir Khan \\ Department of Electrical \\ Engineering University of \\ Engineering \& Technology, \\ Peshawar, Pakistan
}

\author{
Azzam Ul Asar, Ph.D \\ Department of Electrical \\ Engineering University of \\ Engineering \& Technology, \\ Peshawar, Pakistan
}

\author{
Aamir Nawaz \\ Institute of Engineering \& \\ Technology, Gomal University, \\ Dera Ismail khan, Pakistan
}

\begin{abstract}
Poultry farms for meat or egg production is considered to be a huge business. However, waste including manure can give biogas that can produce electricity. In Pakistan load shedding problem remains throughout the year, therefore biomass being the cheap and efficient fuel for power generation can overcome this problem. This research has been conducted in Abbottabad district of Khyber Pakhtunkhwa. Data has been collected from poultry farms for power generation as number of chickens, amount of manure, amount of biogas released and generation of biogas. Biogas plants initial investment has been estimated to be from Rs. 16000 to Rs. 25000 and compared with monthly and annual production of biogas for overall economical variability. Net Value (NV) of electricity, Rate of Return and Payback period has been concluded by Electrigaz application. Large farms with more than 50000 chickens has been very few, while medium with 5001-15000 chickens are bit more in number, and small farms with 5000 chickens are mostly greater in number. Results have showed that large farms payback of biogas plant is upto one year, whereas medium and small farms are two and four years respectively. Biogas and digestate has been produced by anaerobic digestion. The digestate has significant benefits to the agricultural lands, environment and economically. The study concludes that such techniques can enhance power generation and highly control the shortfall of electricity and also intend to run projects for rapid development.
\end{abstract}

\section{General Terms}

Electricity generation, Poultry waste.

\section{Keywords}

Poultry farms, manure, Net Value (NV), Electrigaz, biogas plant

\section{INTRODUCTION}

Poultry farms are considered to be the location where birds, such as turkeys, ducks, chickens etc., are used for meat/egg production and have being diverted to huge business along with hatcheries. The main cause of being importance is the increase in the population. The other uncountable items that are output of the poultry farms are feather and manure, from which mostly the farm can produce biogas and fertilizer. From biogas energy can be generated for electricity [1].

In rural areas most of the manure amount have been recorded. This outcome can be utilized for the production of electricity as in rural area there is a big problem of electricity as compared to urban area. This problem is due to power government system that focuses less towards the rural area, and is under development, having low national grid power station. In linkage to electricity and manure (poultry farms) to very extent can withdraw the problems of rural area of power system other than government by producing biogas converted to electricity $[2,3]$.

Pakistan for many years have been fronting the electricity load shedding. Power shortage is commonly during the year on daily basis but the worse have been recorded to be in summer season. The highest demand recorded for power in percent is thermal energy (oil and gas) with $66.8 \%$ of Pakistan. After thermal the energy demand that comes second is of hydel resources (30\%) and Nuclear energy (3.3\%) [4]. These resources of generating energy are quite expensive due to startup or running cost especially thermal energy and not easily accessible and adjustable in every environment of Pakistan. Nonetheless for attaining individual's demands, society needs alternative strategies like geothermal resources, solar resources, wind resources and biomass resources whereas the last resource is considered to be the most cheap and efficient.

Amjid in [5], presented a review on Biogas as renewable energy in Pakistan. He presented Biogas potential and its comparison with other fuels. In [6], Sheikh has presented a comprehensive review about conventional and renewable energy scenario of the county. Further, he presented review while considering generation, supply and utilization of renewable resources. This research mainly focus on renewable energy installations and planning for future developments.

Zaigham in [7], presented prospects of renewable energies in Pakistan. He proposed share of different energy sources like coal, oil, hydro-electricity and gas for electricity generation and meeting increasing demands. Hill in [8], presented design parameters and operating techniques for anaerobic digestion systems. He has recommended different design parameters for beef waste digestion systems.

This paper gives comprehensive feasibility assessment of generating electricity that from chicken manure of various poultry farms located in Abbotabad. It includes overall setup of farms, optimum technologies for generating electricity from poultry manure.

This paper is organized in such a way as described further. Section 2 contains problem study and data analysis. Section 3 contains results and discussion. Section 4 contains conclusion on basis of results 


\section{PROBLEM STUDY AND DATA}

\section{ANALYSIS}

A case study has been conducted in Khyber Pakhtunkhwa district Abbottabad poultry farms that has been distributed in three kinds, small farms ranged upto 5000 chicken, medium farm 15000 and large farms have 50000 plus chickens. The total estimated amount of farms has been noticed to be $30 \%$ in Abbottabad compared to whole Pakistan..

\subsection{Location of Farms}

Farms comparison of manure settled with each other depending on the environment and location has been studied. Different locations with different environment have critical effects on Biogas production, which will influence electrical generation from that poultry farm.

\subsection{Economical basis of Biogas plants}

Biogas plants accordingly to the manure amount, its plants are develop in $\mathrm{m} 3$ per area in the poultry farms. The preliminary investment assessed on plants range from Rs. 16000 - Rs. 25000 accordingly of manure availability. In table 1 , total investment costs required for $2.4 \mathrm{~m}^{3}$ Biogas Plant is given.

Table 1. Investment costs for materials required for $2.4 \mathrm{~m}^{3}$ Biogas plant

\begin{tabular}{|l|c|c|}
\hline Materials & Amount & Cost (Rs.) \\
\hline Bricks & 1000 & 5000 \\
\hline Sand & $2 \mathrm{~m} 3$ & 850 \\
\hline Bick Chip & $0.6 \mathrm{~m} 3$ & 1100 \\
\hline Cement & 15 bags $(50 \mathrm{~kg} / \mathrm{bag})$ & 4000 \\
\hline Rod & $15 \mathrm{~kg}(10 \mathrm{~mm})$ & 850 \\
\hline $\begin{array}{l}\text { Acrylic Emulsion } \\
\text { Paint }\end{array}$ & 1 litre & 90 \\
\hline Teflon Tape & 3 rolls & 100 \\
\hline Gl Cable & $1.5 \mathrm{~kg}$ & 100 \\
\hline Polythene & 3 meters & 100 \\
\hline
\end{tabular}

In table 2, total investment cost for manpower needed for $2.4 \mathrm{~m}^{3}$ Biogas plant. It includes skilled masons, semi-skilled masons and labours.

Table 2. Investment costs on Manpower required for $2.4 \mathrm{~m}^{3}$ Biogas plant

\begin{tabular}{|l|l|l|}
\hline Manpower & Number of days & Cost (Rs.) \\
\hline Skilled mason & $1-10$ days & 2500 \\
\hline $\begin{array}{l}\text { Semi-skilled } \\
\text { Mason }\end{array}$ & $1-10$ days & 1500 \\
\hline Labour & $1-16$ days & 1200 \\
\hline
\end{tabular}

Table 3 shows total investment for building a $2.4 \mathrm{~m}^{3}$ Biogas Plant for poultry farm.

Table 3. Total Investment costs for $2.4 \mathrm{~m}^{3}$ Biogas plant

\begin{tabular}{|l|l|}
\hline Total Material Cost & 12190 \\
\hline Total Manpower Costs & 5200 \\
\hline $\begin{array}{l}\text { Pipe fitting and other tools } \\
\text { Costs }\end{array}$ & 4000 \\
\hline Total Net Cost & 21390 \\
\hline
\end{tabular}

\subsection{Sampling method}

Survey has been done with farms containing total chickens and records of various types have been estimated, whereas deficiency of information due to any barriers from any farm has been excluded in the study. The estimate utilization of electricity of the farm and the production delivered from the biogas mass has been calculated.

\subsection{Scenario Method}

The two scenarios taken of biogas and electricity generation has been per month and per year total production.

\subsection{Data Analysis}

All data of small, medium and large farms has been analyzed by computer software; Microsoft Excel program to figure out sizes, economically variability and electricity generation. The Net Value (NV) of electricity, Rate of Return and Payback period has been determined. The estimate poultry energy generation calculation of manure has been determined from Electrigaz (Electrigaz, 2007).

The farm of different wattage as electric lamps, fans, water cooler, coal, heater and other equipment's average units has been calculated. These data has compared with poultry waste generating electricity as sample data. To figure out the total potential of the total numbers of bird's layer in Abbottabad district has been taken and magnified at district level.

\section{RESUSTS AND DISCUSSIONS}

Small farms existed more in two areas i.e. Dhamtor and MaugalHattle, with 20 farms per area, and in 35 area there has been such location which had only one farm in those village. Medium farms are total 30 and in a single place are 19 however large farm are a total of 10 . The highest numbers of farms of breeder has been noticed of medium farms, while the least farms has been noticed by 8 farms. The least farms notices are of layer (egg laying chicken as food) with a total of 14 farms.

Results for per year electricity conclude that approximately 34266 units consumed in farms containing up to 50000 chickens. Such farms generate $6103 \mathrm{kWh}$ (Rs. 235395) of the total manure biogas. However farms containing up to 25000 chickens can generate $3051 \mathrm{kWh}$ electricity from the manure biogas with estimate of Rs. 117678. Farms having up to 15000 chickens generate $1831 \mathrm{kWh}$ electricity whereas 1000 or 5000 chickens in farms generate 122 or $610 \mathrm{kWh}$ electricity with estimate cost of Rs. 4586 and Rs. 21081, respectively.

Table 4 shows net budget required per annum for poultry farms while considering different case studies. 
Table 4. Net Budget of Poultry farms per year for different case studies

\begin{tabular}{|c|c|c|c|c|c|}
\hline $\begin{array}{c}\text { Case } \\
\text { Study No. }\end{array}$ & $\begin{array}{c}\text { Number of } \\
\text { Chickens per farm }\end{array}$ & Winter bill & Summer bill & Total bill & Approx. (kWh) \\
\hline $\mathbf{1}$ & 50000 & 420000 & 9000 & 1320000 & 34266 \\
\hline $\mathbf{2}$ & 25000 & 225000 & 480000 & 705000 & 18210 \\
\hline $\mathbf{3}$ & 15000 & 153000 & 324000 & 477000 & 12144 \\
\hline $\mathbf{4}$ & 5000 & 60000 & 126000 & 186000 & 4806 \\
\hline $\mathbf{5}$ & 1000 & 14400 & 30000 & 44400 & 1146 \\
\hline
\end{tabular}

Table 5. Electricity generation and consumption in units (KWh) per year for different case studies

\begin{tabular}{|c|c|c|c|}
\hline $\begin{array}{c}\text { Case Study } \\
\text { No. }\end{array}$ & $\begin{array}{c}\text { Total Units (KWh) Consumed } \\
\text { per Annum without Proposed } \\
\text { System Implementation }\end{array}$ & $\begin{array}{c}\text { Electricity Units (KWh) } \\
\text { Generated per Annum using } \\
\text { Proposed System }\end{array}$ & $\begin{array}{c}\text { Net Units (KWh) Consumed per } \\
\text { Annum with Proposed System } \\
\text { Implementation }\end{array}$ \\
\hline $\mathbf{1}$ & 34266 & 6103 & 28163 \\
\hline $\mathbf{2}$ & 18210 & 3051 & 15159 \\
\hline $\mathbf{3}$ & 12144 & 1831 & 419311 \\
\hline $\mathbf{4}$ & 4806 & 610 & 1024 \\
\hline $\mathbf{5}$ & 1146 & 122 & 4196 \\
\hline
\end{tabular}

Table 5 shows electricity generation and consumption in poultry farms for different case studies.

Beside electricity generated from the manure, the end product considered as waste also known as digestate are used as fertilizer. It includeds phosphorus, nitrogen and additional heavy metals that are significantly benefits agricultural lands with environment friendly impact. Results shows that farm containing 50,000 chickens have estimate bill of Rs. 80,000 and farm of 25000 chickens with Rs. 45,000. Similarly 15,000 chickens farm bills of Rs. 60,500 where 5000 and 1000 chicken's farms have around Rs. 20,000 and Rs. 5000monthly bills. Per month biogas production in small farms is recorded with average of $1400 \mathrm{~m} 3$. In medium farm per month biogas production observed is with average of $4500 \mathrm{~m} 3$, while 7200 m3 annually. Large farms production of biogas recorded are $15960 \mathrm{~m} 3$ per month and $194180 \mathrm{~m} 3$ annually. The electricity generated per year with average of $366 \mathrm{kWh}, 1526 \mathrm{kWh}$ and $4272 \mathrm{kWh}$ from small, medium and large farms chicken manure biogas.

Table 6: Electricity generation in units (KWh) and savings from proposed system

\begin{tabular}{|c|c|c|}
\hline $\begin{array}{c}\text { Case Study } \\
\text { No. }\end{array}$ & $\begin{array}{c}\text { Generated Units (KWh) per Annum with } \\
\text { Proposed System }\end{array}$ & $\begin{array}{c}\text { Approx. Savings } \\
\text { (Rs) }\end{array}$ \\
\hline $\mathbf{1}$ & 6103 & 235395 \\
\hline $\mathbf{2}$ & 3051 & 117678 \\
\hline $\mathbf{3}$ & 1831 & 69826 \\
\hline $\mathbf{4}$ & 610 & 21081 \\
\hline $\mathbf{5}$ & 122 & 4586 \\
\hline
\end{tabular}

\section{CONCLUSION}

From poultry farms manure electricity can be generated as well as the digestate, functioning as fertilizer. The optimization procedure can be stabilized by solving technical barriers, awareness, financial issues, proper understanding and managing the needs of electricity. Moreover, the repair and maintenance cost of the biogas plant and its connected generator will be adjusted from the amount generated after selling the digestate (which is a good quality fertilizer) to the local farmers. In future studies, biogas power generation can be integrated in a power system with other renewable energies for increasing power system's reliability..

\section{REFERENCES}

[1] FAO .2008. Poultry in the 21st century: avian influenza and beyond. Proceedings of the International Poultry Conference, Bangkok, 5-7 Nov. 2007, edited by O. Thieme and D. Pilling. FAO Animal Production and Health Proceedings No. 9. Rome.www.fao.org/againfo/resources/en/pubs_aprod.ht $\mathrm{ml}$.

[2] Nahm, Kee Hong, and B. A. Nahm. "Poultry production and waste management."(2004). Republic of Korea, Yu Han Publishing.ISBN 89-7722-623-6. 
[3] Williams, M., Barker, J. \& Sims, J. 1999. Management and utilization of poultry wastes. Rev Environ ContamToxicol., 162: 105-157.

[4] M. A. Uqaili, K. Harijan and M. Memon, "Prospects of Renewable Energy for Meeting Growing Electricity Demand in Pakistan," AIP Conf.Proc.Vol. 941, pp. 5361, October 2007.

[5] S. S. Amjid, M. Q. Bilal, M.S. Nazir, A. Hussain, "Biogas, Renewable Energy Resource for Pakistan," Renewable and Sustainable Energy Reviews, pp: 28332837, 2011.
[6] M. A. Sheikh, "Energy and Renewable Energy Scenario of Pakistan," Renewable and Sustainable Energy Reviews, pp: 354-363, 2010.

[7] N. A. Zaigham and Z. A. Nayyar, "Prospects of Renewable Energy Sources in Pakistan," Proc. of COMSATS Conf. Renewable Energy Technologies and Sustainable Development, 2005.

[8] D. Hill, "Design Parameters and Operating Characteristics of Animal Waste Anaerobic Digestion Systems. Beef Cattle," Agricultural Wastes, 5 (1983): 205-218. 